\title{
Correlation between Serum Level of Antiepileptic Drugs and their Side Effects
}

\author{
Abbashar Hussein, ${ }^{1}$ Amira Abdulgalil, ${ }^{2}$ Faroug Omer, ${ }^{3}$ Hassan Eltoum, ${ }^{3}$ Ahmed Hamad, ${ }^{4}$ Omer El-Adil, \\ Bedraldin Mubarak, ${ }^{6}$ Mohmad Malkaldar, ${ }^{6}$ Iway Idris, ${ }^{6}$ Yasin Alwidaa, ${ }^{6}$ Esam Mahmoud ${ }^{6}$
}

\section{Abstract}

Objectives: The aim of the study is to investigate the relation between serum levels of anticonvulsants and their side effects.

Methods: This is a prospective cross sectional hospital based study conducted at Al Shaab Teaching Hospital. 120 patients were included in the study. The AEDs used were phenytoin, phenobarbitone, carbamazibine, and sodium valproate.

Results: The results showed that the side effects among the studied group were not uncommon.

Conclusion: There was no relationship between serum levels of AEDs and their side effects.
From the ${ }^{1}$ Department of Medicine, University of Khartoum, Africa, ${ }^{2}$ Department of FAMCO, University of Elnilin, Africa, ${ }^{3}$ Department of Medicine, Omdurman Islamic University, Africa, ${ }^{4}$ Department of Medicine, Babr Elgazal University, Africa ${ }^{5}$ Department of Medicine, AfricaUniversity, Africa, ${ }^{6} \mathrm{Federal}$ Ministry of Health, Sudan, Africa.

Received: 07 Sep 2009

Accepted: 03 Nov 2009

Address correspondence and reprint requests to: Dr. Abbashar Hussein, Department of Medicine, University of Khartoum, Sudan, Africa.

E-mail:abbashar59@yahoo.com

Hussein A, et al. OMJ. 25, 17-21 (2010); doi:10.5001/omj.2010.5

\section{Introduction}

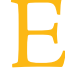
pilepsy is a relatively common condition characterized by a tendency for recurrent seizures, which is due to the disturbance of spread of electrical discharge of the cortical neurons. ${ }^{1-2}$ Up to $80 \%$ of people with epilepsy are able to control their condition with AEDs. The type of drug therapy prescribed depends on the type of seizure, the underlying cause of the epilepsy, age of the patient and possible side effects. Treatment usually starts with one drug at a low dose. The dose is then increased slowly. In most patients, epilepsy remits over a period of years and drug therapy may be withdrawn slowly.

Phenytoin is effective for the treatment of partial and tonicclonic seizures. ${ }^{3}$ Carbamazepine is effective for the treatment of partial and generalized tonic-clonic seizures. Whereas Phenobarbitone is as effective as phenytoin and carbamazebine in abolishing partial and generalized tonic-clonic seizures. On the other hand, Sodium valproate is effective in patients with all types of seizures. Monitoring of plasma or serum concentrations of the older antiepileptic drugs phenobarbitone and phenytoin began to come into use in the late $1960 \mathrm{~s}^{4}$

Plasma concentration monitoring is now widely used not only for phenobarbitone and phenytoin, but for the other longer established antiepileptic drugs carbamazepine, valproate and ethosuximide. ${ }^{5}$ The antiepileptic drugs that have been marketed in recent years have not yet been subjected to any widespread monitoring in clinical practice. The plasma (or serum) therapeutic ranges (or therapeutic 'windows') for most of the antiepileptic drugs have been published. The benefits of the monitoring lie in enhanced efficiency of antiepileptic treatment, with more rapid achievment of satisfactory drug dosage, fewer and earlier recognized overdosage-type adverse effects and more readily detected noncompliance with therapy.

\section{Methods}

This is a descriptive cross sectional hospital based study. It was conducted at Al Shaab Teaching Hospital (tertiary hospital), Khartoum town. The study population included 120 adult Sudanese epileptic patients referred to the hospital from Feb 2004 to Feb 2008 .

All the study patients were newly diagnosed and were not on treatment. At first, 130 patients were included in the study but 10 patients were dropped due to the difficulty of follow up, the rest of the patients were followed by the authors for three years. All the patients were adult Sudanese; those below 18 years of age were excluded. All patients gave their verbal consent to participate in the study. Ethical approval was received from the local ethics committee prior to the start of the study. Phenytoin was used in the treatment of both generalized and partial epilepsies. The starting dose was $100 \mathrm{mg}$ and the daily dose was $300 \mathrm{mg}$, given in 1-3 doses per day. The standard maintained dose was 100$500 \mathrm{mg}$ and the normal plasma drug concentration was 10-20 ug/ $\mathrm{ml}$. Phenobarbitone was indicated in cases of generalized Epilepsy. The starting dose was $30 \mathrm{mg}$; the normal daily dose was 60-90 $\mathrm{mg}$, given in 1-3 doses per day. The standard maintence dose was $60 \mathrm{mg}$. The normal plasma drug concentration was $10-40 \mathrm{ug} / \mathrm{ml}$.

Carbamazepine was used for the treatment of both partial and secondary generalized Epilepsy. The starting dose was 200 $\mathrm{mg}$, the daily dose was $600 \mathrm{mg}$ given in 1-4 dose/day, the standard maintence dose was 400-1200 mg the plasma drug concentration was 6-12 ug/ml. Sodium valproate was used for the treatment of both partial and generalized Epilepsy. $200 \mathrm{mg}$ was the starting dose; the daily dose was $600 \mathrm{mg}$, given in 1-3 doses with the standard maintence dose of 600-1000 mg.

The normal plasma drug concentration was 50-100 ug/ml. Blood 
samples to determine drugs plasma concentrations were obtained 6 weeks after starting the treatment, a second sample was taken after 6 months and a third sample after one year, while the last sample was obtained after two years. Particular attention was focused on regular monthly follow up of the patients on the following; (1) whether the patients were compliant to the drug regimens (2) whether they experienced an attack of convulsion or not (3) history of symptoms of drugs intoxication and proper examination of each patient to determine the signs of drug toxicity. The data was collected by a self administered questionnaire, all collected data was finally entered on the computer using the statistical package program for social science (SPSS) to analyze the data using simple descriptive statistics

\section{Results}

The distribution of 120 epileptic patients according to antiepileptic drugs they received was as follows; 45 patients received phenytoin, 42 patients received Phenobarbitone, 35 received carbamazepine and 38 patients received sodium valproate (40 patients received more than one drug). Out of 120 patients, $80(66.6 \%)$ took one drug, while $40(33.3 \%)$ patients received more than one drug. Regarding Idiosyncratic side effects, out of 45 patients on phenytoin, five had acne, four had skin rash, four had coarse facial appearance, one had blood dyscrasias, one had Steven-Johnsons syndrome, and one patient had duptuytrens contracture.
Dose related side effects of phenytoin were found as followed: out of 45 patients who received phenytoin four had nausea and vomiting, four had gum hypertrophy, four had drawziness, three had ataxia, three had nystagmus and one patients had megaloblastic anaemia.

Out of 42 patients who received Phenobarbitone; four had skin rash (Idiosynchratic). While the dose-related side effects of Phenobarbitone included; fatigue experienced by five patients, two had listlessness, two experienced depression, one had insomnia, one had irritability and one patient had distractibility and hyperkinasia.

The idiosynchratic adverse effects of carbamazepine were found as follows; four patients had skin rash, one patient had Agranulocytosis and one patient had aplastic anaemia. Regarding the incidence dose related adverse effects of carbamazebine, out of 38 patients; five had nausea and vomiting, four had sleepiness, three had drawziness, three had neutropenia, two had dizziness, and one had headache, while one patient experienced hyponatraemia.

Out of 38 patients who received sodium valproate, only one experienced thrombocytopenia and one patient experienced encephalopathy. Regarding dose related side effects of sodium valproate, out of 35 patients; four had weight gain, three had tremor, three had irregular cycles, two had nausea and vomiting while two patients experienced hair loss.

Table 1: Shows the incidence of idiosyncheratic adverse effects of phenytoin (among 45 patients), phenobarbitone (42 patients), carbamazepine ( 35 patients) and Sodium valproate (38 patients).

\begin{tabular}{|c|c|c|c|c|}
\hline Side Effect & Phenytoin & Phenobarbitone & Carbamazepine & Sodium Valproate \\
\hline SLE-like Syndrome & 1 & & & \\
\hline Hepatotoxic effect & 1 & & 1 & \\
\hline \multicolumn{5}{|l|}{ Stevens-Johnsons Syndrome } \\
\hline Dupuytren contracture & 1 & & & \\
\hline \multicolumn{5}{|l|}{ Teratogenicity } \\
\hline Acne & 5 & & & \\
\hline Skin Rash & 4 & 4 & 4 & \\
\hline Coarse Facial Appearance & 4 & & & \\
\hline Blood Dyscrasia & 1 & & & \\
\hline \multicolumn{5}{|l|}{ Lymph Adenopathy } \\
\hline \multicolumn{5}{|l|}{ Chorea } \\
\hline Agranulocytosis & & & 1 & \\
\hline Aplastic Anaemia & & & 1 & \\
\hline \multicolumn{5}{|l|}{ Erythema multiforme } \\
\hline \multicolumn{5}{|l|}{ Pancreatitis } \\
\hline Encephalopathy & & & & \\
\hline Thrombocytopenia & & & & 1 \\
\hline
\end{tabular}


Table 2: Dose related side effects of Phenytoin, Phenobarbitone, Carbamazepine and Sodium Valproate.

\begin{tabular}{|c|c|c|c|c|}
\hline Side Effect & Phenytoin & Phenobarbitone & Carbamazepine & Sodium Valproate \\
\hline Nausea & 4 & & & \\
\hline Vomiting & 4 & & & \\
\hline Ataxia & 3 & & & \\
\hline Nystagmus & 3 & & & \\
\hline Gingival Hypertrophy & 4 & & & \\
\hline Megalblastic Anemia & 1 & & & \\
\hline \multicolumn{5}{|l|}{ More fit } \\
\hline Drowziness & 4 & 4 & 3 & \\
\hline Listlessness & & 2 & & \\
\hline Fatigue & & 5 & & \\
\hline Depression & & 2 & & \\
\hline Insomnia & & 1 & & \\
\hline Irritability & & 1 & & \\
\hline Sleepiness & & 5 & & \\
\hline Nausea $\&$ vomiting & & & 5 & 2 \\
\hline Neutropenia & & & 3 & \\
\hline Diplopia & & & 2 & \\
\hline Dizziness & & & 2 & \\
\hline Headache & & & 1 & \\
\hline Hyponatraemia & & & 1 & \\
\hline \multicolumn{5}{|l|}{ Arrthymia } \\
\hline \multicolumn{5}{|l|}{ Orofacial Dyskinesia } \\
\hline Tremor & & & & 3 \\
\hline Weight Gain & & & & 4 \\
\hline Menstrual Cycle disturbance & & & & 3 \\
\hline Alopecia & & & & 2 \\
\hline \multicolumn{5}{|l|}{ Peripheral Edema } \\
\hline Steepness & & & 4 & \\
\hline
\end{tabular}

Table 3: Serum level distribution of Phenytoin, Phenobarbitone, Carbamazebine and Sodium valproate.

\begin{tabular}{lcc}
\hline Drug & Normal serum distrbution & Abnormal serum distribution \\
\hline Phenytoin & $38(10-20 \mathrm{mg} / \mathrm{ml})$ & 7 \\
Phenobarbitone & $37(10-40 \mathrm{mg} / \mathrm{ml})$ & 5 \\
Carbamazepine & $27(6-12 \mathrm{mg} / \mathrm{ml})$ & 8 \\
Sodium Valproate & 33 & 5 \\
\hline
\end{tabular}

Table 3 shows the serum level distributions of the anti-epileptic drugs. Out of 45 patients who received phenytoin, 38 had normal serum levels while 7 showed increased serum levels of the drug.

While the distribution of serum levels in patients who received Phenobarbitone showed that 37 patients had normal serum levels of the drug, compared to five patients who had increased serum levels of the drug.

The distribution of serum levels of carbamazebine were found as follows; 30 patients had a normal serum levels while two patients had abnormal serum levels (increased).
On the other hand, the distribution of serum levels of sodium valproate showed that 33 patients had normal serum levels of the drug, while only five patients had abnormal levels (increased).

It appeared that most of the patients (60\%) who showed some evidence of side effects due to the AEDs had normal serum levels of the AEDs, hence $30 \%$ of these patients took more than one AED. The study showed that 62 patients (52\%) became seizure-free during the treatment period ( 3 years) while 58 patients $(47.33 \%)$ still experienced convulsions. 


\section{Discussion}

AEDs are a major treatment consideration for patients with epilepsy and therefore, the main concern for choosing an appropriate drug and dosage is the efficient control of seizures. A number of factors including patient age, polypharmacy increase the risk of side effects of AEDs. The distribution of side effects of the drugs used in this study was found to be similar to what was mentioned in the literature. ${ }^{4-5}$ Also, like what was reported by other researchers, the results from this study showed that there was no relationship between serum levels of AEDs and their side effects. ${ }^{6-7}$ The occurrence of adverse effects unrelated to the dose, is particularly prominent during the initiation of therapy (especially with carbamazepine and valproic acid), but disappear as tolerance develops.

For this reason, therapy with these drugs should be started on low doses and the dose slowly titrated up to the recommended maintenance over several weeks. Transient neurotoxicity during the first hours following drug ingestion may relate to an excessive fluctuation in plasma concentrations between doses and high peak plasma concentrations. These peak plasma concentration-related neurologic effects commonly result from the use of inappropriate dosage intervals relative to the drug half-life or administration of rapidly absorbed dosage formulations. Most of the adverse effects are dose-related and more prominent at higher AED plasma concentrations.

Although the severity and frequency of adverse effects may vary among the agents, the concentration-related adverse effects are qualitatively similar among the different AEDs and are observed in all patients if large enough doses are given. The occurrence of these adverse effects end up being the therapy limiting endpoint for most patients. Due to additive neurologic effects of the AEDs, the adverse effects are more frequent and occur at lower plasma concentrations in patients receiving AED polytherapy (i.e. more than one AED). The occurrence and severity of these neurologic side effects can be minimized by:

a. Initiating therapy at a low dose and slowly increasing the dose

b. Avoiding large dosage changes

c. Restricting therapy to one drug when ever possible

d. Adjusting the administration schedule (e.g. administration of the largest dose at bedtime, dividing the daily dose into smaller doses given more frequently)

e. If the occurrence of these adverse effects is primarily associated with the time of peak serum concentrations, their occurrence may be reduced by administering smaller doses more frequently or switching to a more slowly absorbed formulation.

f. Reduction in total daily dose.
Phenytoin acts by inducing voltage-dependent and usedependent blockade of sodium channels. Phenytoin is one of a handful of drugs for which the kinetics change from the first order 'in which the extent of metabolism is directly correlated with the amount of available drug' to saturation at therapeutic doses. Accordingly, at plasma concentration of around 15 ug per $\mathrm{ml}$, a moderate increase in the dose can cause an unexpectedly large rise in plasma concentration. A starting dose of $5 \mathrm{mg}$ per kilogram of body Weight raises plasma concentrations with the target range total of 20 ug per $\mathrm{ml}$ in most patients, but some have higher concentrations and neurotoxic effects.

Other patients require a higher dose for example, those who abuse alcohol and have increased hepatic microsomal enzymes nativity. In general, the dose can be increased by $100 \mathrm{mg}$ if the plasma drug concentration is 8 ug per $\mathrm{ml}$ or less, but no more than $50 \mathrm{mg}$ should be added if the plasma drug concentration is higher. Some patients can benefit from plasma concentrations above 25 ug per $\mathrm{ml}$ without duties effects. Pheytoin can cause a range of dose-related and idiosyncheratic adverse effects. Reversible cosmetic changes (gum hypertrophy, acne, hirsutism, and facial coarsening), although they tend to be mild, can be troublesome. Neurotoxic symptoms (drowsiness, dysartheria, tremors, ataxia, and cognitive difficulties) become increasingly likely when the plasma drug concentration exceeds 20 ug per ml. ${ }^{6-7}$

Phenobarbitone at the cellular level prolongs inhibitory postsynaptic potentials by increasing the mean chloride-channel opening time and hence the duration of $\mathrm{r}$-amino butyric acidinduced bursts of neuronal activity. ${ }^{8-9}$ The main limitation of phenobarbitone is its propensity to alter cognition, mood, and behavior. The drug can cause fatigue and listlessness, skin rash, sleepiness and drowziness, these are the common side effects observed. Tolerance of the deleterious cognitive effects of phenobarbitone can develop, but unfortunately, tolerance of its anticonvulsant effect can also develop. To minimize the sedative effect, the starting dose should be low ' $30 \mathrm{mg}$ ' and increased gradually according to the response. The value of measuring plasma phenobarbitone concentrations is limited, because the concentration associated with optimal control varies considerably. In addition, the development of tolerance to the drug and central nervous system side effects makes the toxic threshold imprecise.

Carbamazepine acts by preventing repetitive firing of action potentials in depolarized neurons through voltage-dependent and used-dependent blockades of sodium channel ${ }^{10-11}$ Sleepiness, nausea, vomiting, drowziness, skin rash and diplopia are the most common side effects of carbamazebine. These symptoms limit the dose in many patients with refractory epilepsy. In addition high peak plasma concentrations can result in intermittent central 
nervous system side effects in approximately two hours after ingestion of the drug, necessitating administration three or four times daily in some patients. This problem can be overcome by prescribing controlled-release formulation which can be given once or twice daily.

Carbamazepine can cause a range of idiosynchratic reactions, the most common is a morbiliform rash, which developed in around $10 \%$ of patients. Less common skin eruptions include erythema multiforme. Reversible mild leucopenia is common but dose not require discontinuation of therapy, unless there is evidence of infection or the leukocytes count falls below 2.000.000 per cubic millimeter. Blood dyscrasias and toxic hepatitis are very rare. At high plasma concentrations, carbrazebime has an antidiuretic hormone-like action. The resulting hyponatremia is usually mild and asymptomatic, but if the plasma sodium concentration falls below $125 \mathrm{mmol}$ per litre, there may be confusion, peripheral oedema and decreased control of seizures. Orofacial duskinesias and cardiac arrhythmias are additional but rare side effects.

Treatment with carbamazebine should be initiated at low dose (200 per day) to allow tolerance of its central nervous system side effects to develop. The dose can then be increased by increments of 200 per day at interval of two to four weeks until a maintenance dose has been reached that controls the seizure disorder completely. Out of 35 patients, eight had a plasma levels more than the normal range. The substantial dose variations between plasma carbamazebine concentrations with twice daily doses makes the interpretation problematic in many patients; the dose can be titrated adequately with the use of clinical criteria alone. Exceptions include patients whom are non-compliant or those taking more than one antiepileptic drugs, which are likely to interact with carbamazebine.

Sodium valproate is effective in patients with all types of seizures, and especially in those with idiopathic generalized epilepsy. ${ }^{12-13}$ The drug acts by limiting sustained repetitive neuronal firing through voltage-dependent and use-dependent blockade of sodium channels, although it is also likely to have other effects. ${ }^{14-15}$ The common sides effect of sodium valproate are dose-related, such as tremor, weight gain (which is due to appetite stimulation), thinning or loss of hair (usually temporary) and menstrual irregularities, including amenorrhea. Sedation is unusual, although stupor and encephalopathy rarely occur, also the incidence of hepatotoxic effect is very low, but such effects are of concern in children under three years of age who are receiving multiple antiepileptic drugs.

The starting dose for adults is $500 \mathrm{mg}$ once or twice daily, with subsequent increase according to the response. Sodium valproate can take several weeks to become fully effective, the dose should not be increase sooner. The study showed that there was no clear cut relationship between the plasma concentration of sodium valproate, its effect and toxicity, and since the daily variation in plasma concentration is wide, routine monitoring may not be helpful unless it is correlated with the patients clinical situation. ${ }^{15}$

One of the study limitation is that serum levels of AEDs can be affected by more than one factor eg genetic, environmental, nutritional factors and diseases like liver and renal diseases.

\section{Conclusion}

There was no correlation between serum levels of the AEDs and their side effects, therefore, the diagnosis of AED related toxicity should be made on clinical grounds.

\section{Acknowledgements}

The authors reported no conflict of interest and no funding has been received on this work.

\section{References}

1. Berkovic SF, McIntosh A, Howell R. Familial temporal lobe epilepsy: A common disorder identified in twins. Ann Neurol 1996; 40:227-235.

2. Raymond AA, Fish DR, Sisodiya SM. Abnormalities of gyration, heterotopias, tuberous sclerosis, focal cortical dysplasia, microdysgenesis, dysembryoplastic neuroepithelial tumour and dysgenesis of the archicortex in epilepsy. Brain 1995; 118(3):629-660.

3. Taylor DC, Falconer MA, Bruton CJ. Focal dysplasia of the cerebral cortex in epilepsy. J Neurol Neurosurg Psychiat 1971; 34:369-387.

4. Palmini A, Andermann F, Olivier A. Focal neuronal migration disorders and intractable epilepsy: a study of 30 patients. Ann Neurol 1991 Jan; 30(6):741749 .

5. Lüders $\mathrm{HO}$, Burgess $\mathrm{R}$, Noachtar S. Expanding the international classification of seizures to provide localization information. Neurology 1993; 43:1650-1655.

6. Lüders H, Acharya J, Baumgartner. Semiological seizure classification. Epilepsia 1998; 39:1006-1013.

7. Engel J. Classification of the international league against epilepsy: Time for reappraisal. Epilepsia 1998; 39:1014-1017.

8. Hirsch LJ, Arif H, Nahm EA, Buchsbaum R, Resor SR Jr, Basil CW. Crosssensitivity of skin rashes with antiepileptic drug use. Neurology 2008 Nov; 71(19):1527.

9. Loscher W, Klotz U, Zimprich F, Schmidt D. The clinical impact of pharmacogenetics on the treatment of epilepsy. Epilepsia 2009; 50:51.

10. Asconape JJ. Some common issues in the use of antiepileptic drugs. Semin Neurol 2002 Mar; 22(1):27.

11. Cramer JA, Mattson RH. Compliance with antiepileptic drug therapy. In: Levy RH, Mattson RH, Meldrum BS, eds, Antiepileptic Drugs, 4th ed, New York, Raven Press, 1995: 149-159.

12. Kyngas H. Compliance with health regimens of adolescents with epilepsy. Seizure 2000; 9:598-604.

13. Kubotsu K, Goto S, Fujita M, Tuchiya H, Kida M, Takano S, et al. Automated homogeneous liposome immunoassay systems for anticonvulsant drugs. Clin Chem. 1992;38:808-812.

14. McGlone R, Pritty P. Measuring anticonvulsant levels in the accident and emergency department. Arch Emerg Med 1986 Jun; 3(2):141-143.

15. Schoenenberger RA, Tanasijevic MJ, Jha A, Bates DW. Appropriateness of antiepileptic drug level monitoring. J Am Med Assoc 1995 Nov; 274(20):1622-1626. 